\title{
Objective Assessment of Olfactory Function Using Functional Magnetic Resonance Imaging
}

\author{
Adolfo Toledano, Susana Borromeo, Guillermo Luna, Elena Molina, \\ Ana Beatriz Solana, Pablo García-Polo, Juan Antonio Hernández, \\ Juan Álvarez-linera
}

\begin{abstract}
Objective: To show the results of a device that generates automated olfactory stimuli suitable for functional magnetic resonance imaging ( $\mathrm{FMRI}$ ) experiments.

Material and methods: Ten normal volunteers, 5 women and 5 men, were studied. The system allows the programming of several sequences, providing the capability to synchronise the onset of odour presentation with acquisition by a trigger signal of the MRI scanner. The olfactometer is a device that allows selection of the odour, the event paradigm, the time of stimuli and the odour concentration. The paradigm used during fMRI scanning consisted of 15-s blocks. The odorant event took $2 \mathrm{~s}$ with butanol, mint and coffee.

Results: We observed olfactory activity in the olfactory bulb, entorhinal cortex (4\%), amygdala $(2.5 \%)$ and temporo-parietal cortex, especially in the areas related to emotional integration. Conclusions: The device has demonstrated its effectiveness in stimulating olfactory areas and its capacity to adapt to fMRI equipment.
\end{abstract}

Estudio objetivo del olfato mediante resonancia magnética funcional

Resumen

Objetivo: Mostrar los resultados del olfatómetro capaz de generar tareas olfativas en un equipo de resonancia magnética funcional ( $\mathrm{fMRI}$ ). 
Olfatómetro;

Retroalimentación
Material y métodos: Estudiamos 10 sujetos normales: 5 varones y 5 mujeres. El olfatómetro está diseñado para que el estímulo que produce se sincronice con el equipo de fMRI mediante la señal desencadenante que suministra el propio equipo. El olfatómetro es capaz de: seleccionar el olor, secuenciar los distintos olores, programar la frecuencia y duración de los olores y controlar la intensidad del olor. El paradigma utilizado responde a un diseño de activación asociada a eventos, en el que la duración del bloque de activación y de reposo es de $15 \mathrm{~s}$. La duración del estímulo olfativo (butanol, menta o café) es de 2 segundos, durante toda la serie que consta de 9 ciclos.

Resultados: Se ha observado reactividad (contraste BOLD) en las diferentes áreas cerebrales involucradas en las tareas olfativas: bulbo olfatorio, córtex entorrinal (4\%), amigdala $(2,5 \%)$ y córtex temporoparietal. Las áreas relacionadas con integración de las emociones tienen una reactividad mayor.

Conclusiones: El dispositivo propuesto nos permite controlar de forma automática y sincronizada los olores necesarios para estudiar la actividad de las áreas olfatorias cerebrales mediante fMRI.

\section{Introduction}

It is estimated that in the United States there are 2.7 million people who suffer from olfactory disorders, i.e. about $1.4 \%$ of the total population. Approximately 200000 Americans each year suffer a smell or taste problem. ${ }^{1,2}$ In our practice, $1.7 \%$ of patients each month report a smell disorder as the main reason for consultation. ${ }^{3}$

The objective study of smell in humans is still an unresolved problem. The reasons for this are probably manifold. One possible factor is that man gives less importance to this sense than to others, such as sight and hearing. On the other hand, there are still various anatomical-physiological questions which remain unanswered, making it difficult to establish a correlation between an olfactory stimulus and an objective test, either electrophysiological or imaging. ${ }^{4}$ Another problem is the difficulty of adequately controlling olfactory stimuli in terms of intensity and duration, in order to correlate a specific stimulus with the response elicited. ${ }^{5}$

The first attempt to study smell objectively took place in the late 1960 s of the past century, and employed the electrophysiological recording of odours. ${ }^{6}$ At present, the electrophysiological study of smell is done by electro-olfactograms ${ }^{7}$ and olfactory evoked potentials. ${ }^{8}$ An electro-olfactogram involves the collection of electrical activity in the nasal olfactory epithelium through the application of intranasal electrodes. Olfactory evoked potentials consist in the collection of electrical activity (olfactory bulb and/or frontal cortex) using external electrodes. Both techniques employ expensive apparatus and take a long time. They are eminently used in research and therefore are not performed normally in daily practice.

Moreover, functional magnetic resonance imaging (fMRI) studies can detect brain activity when subjects perform psychocognitive, sensory or motor tasks. fMRI imaging enables the noninvasive study of brain activity while subjects perform a particular task, by detecting small signal changes dependent on blood oxygen level (BOLD signal). These changes are the result of a neural response induced by repeated cycles of stimulation conditions (i.e. experimental conditions) and resting conditions (i.e. control conditions). In recent years, functional neuroimaging has become a very promising technique as a tool for the analysis of the olfactory system. ${ }^{9}$ One problem with these devices is the need to coordinate the stimulus, whatever this may be, with the collection of images. Furthermore, fMRI is not compatible with the use of metal devices inside the same room.

The aim of this work is to show the results among normal subjects of an olfactometer capable of generating olfactory tasks in the context of an fMRI study of brain activity.

\section{Material and Methods}

The olfactometer developed at the Department of Electronic Technology of Universidad Rey Juan Carlos has been designed specifically for olfactory stimulation. It automatically generates olfactory stimuli which are suitable for fMRI experiments, as it synchronises the olfactory task with the acquisition of magnetic resonance imaging (MRI) through the trigger signal of the scanner. It produces a selective and controlled stimulation of the olfactory system. Among the parameters that can be controlled are the selection and sequencing of odours, the frequency and duration of stimuli and the intensity of the stimulus.

Fig. 1 shows a schematic of the device. It consists of several dispensers (up to 8 ) which receive an air flow regulated by a flowmeter. The choice of odour is done by actuating specific electrovalves. After the air pump are two filters, one for particles and another with activated carbon, for the removal of other odours which could be introduced accidentally. A computer with a sequence control board enables the opening and closing of the electrovalves, as well as synchronisation of the stimuli with image acquisition.

A specific software program has also been developed in order to design olfactory tasks, so they can be executed automatically and remotely during image acquisition. The MRI data were obtained with a $3 \mathrm{~T}$ General Electric MRI scanner located at Centro Alzheimer Fundación Reina Sofía (Fig. 2). The fMRI sequence used was a gradient-echo functional sequence with echo-planar k-space acquisition. The GE-EPI (gradient-echo echo-planar imaging) sequence acquisition parameters were as follows: RT (repetition time) $=3 \mathrm{~s}$, ET (echo time) $=$ minimum full, FA (flip angle) $=90^{\circ}$, matrix of $96 \times 128$ samples, FOV (field of view) $=22 \mathrm{~cm}$, section thickness of $2.4 \mathrm{~mm}$, space of $0 \mathrm{~mm}$ between sections and full volume of 34 sections. 


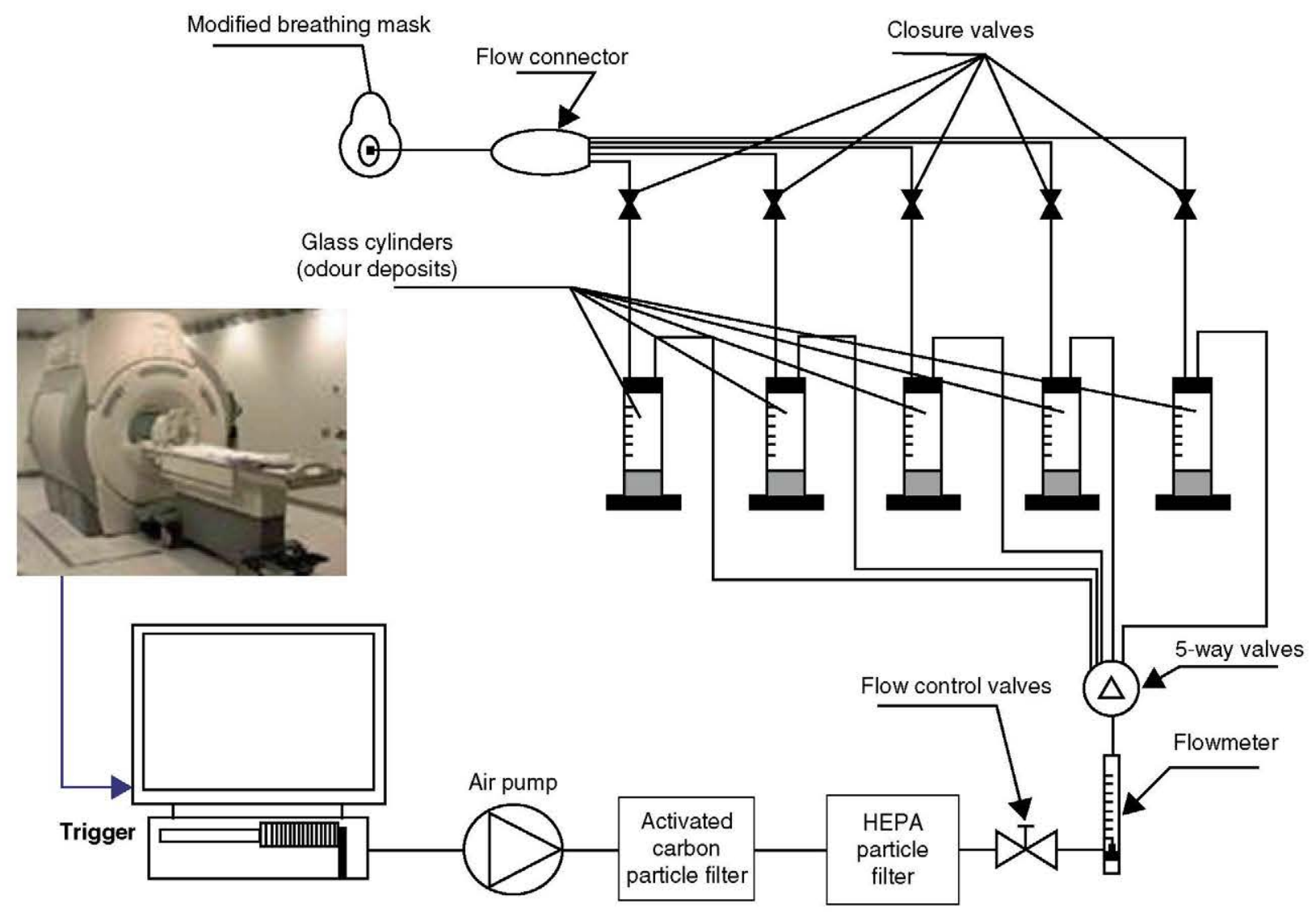

Figure 1 MRI-compatible olfactometer. The diagram shows how the image acquisition signal from the fMRI device activates the olfactometer software. In turn, the olfactometer software regulates the opening of the electrovalves to release the odours stored in the canisters. The odours travel through the tube up to the mask worn by the subject.

Two types of paradigms were designed for functional imaging: block design and event-related activation design. Only the results obtained with the event-related activation design are shown, since it was the most effective way to visualise brain activation associated with an olfactory stimulus and to eliminate the effects of habituation of the primary olfactory cortex (POC). ${ }^{10}$

The paradigm used responded to an event-related design, in which the duration of activation and resting blocks was $15 \mathrm{~s}$. The duration of the olfactory stimulus (butanol, mint or coffee) was $2 \mathrm{~s}$ for the entire series, which consisted of 9 cycles (Fig. 3). Breathing was recorded by "respiratory gating", for later use in data processing. The protocol did not include "sniffing" and, therefore, subjects did not know when the olfactory stimulus would be presented.

The following transformations were applied to the fMRI images prior to data analysis: 3D motion correction, temporal high-pass filtering set to the stimulation paradigm, temporary correction and spatial smoothing.

So as to avoid inter-subject and intra-subject variability, analysis was conducted by regions of interest (ROI), through a segmentation of subcortical/cortical structures.

Functional images were constructed by convolving a sequence of square pulses of 2-s duration. These pulses were synchronised with the application of olfactory stimuli with the canonical haemodynamic response function (HRF)
(Fig. 4). The registration of breathing was used as a regressor in the analysis.

The analysis of study results was performed using the software tool SPM8 (statistical parametric mapping) developed by University College London for neuroimaging data analysis. ${ }^{11}$

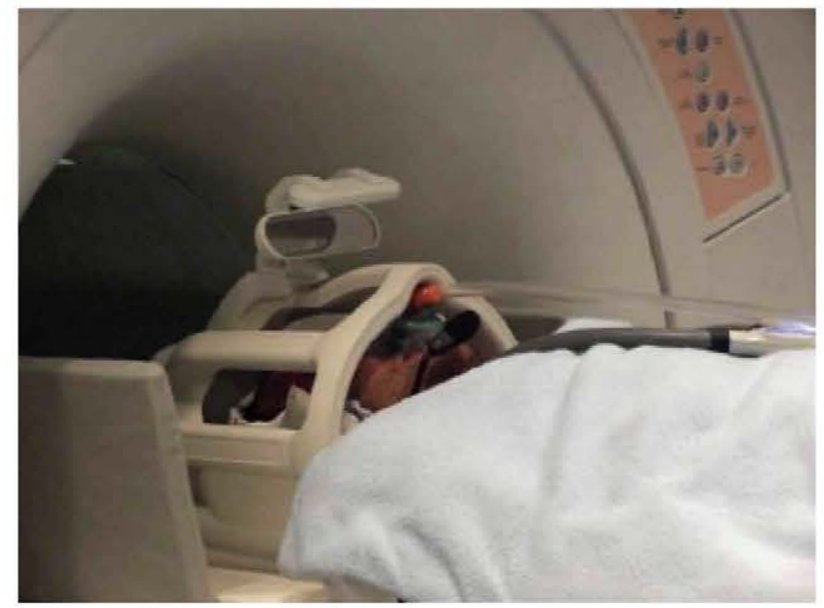

Figure 2 Volunteer subject wearing the dispenser mask. As shown by the image, the mask may create a space conflict and cramped feeling for the subject. 


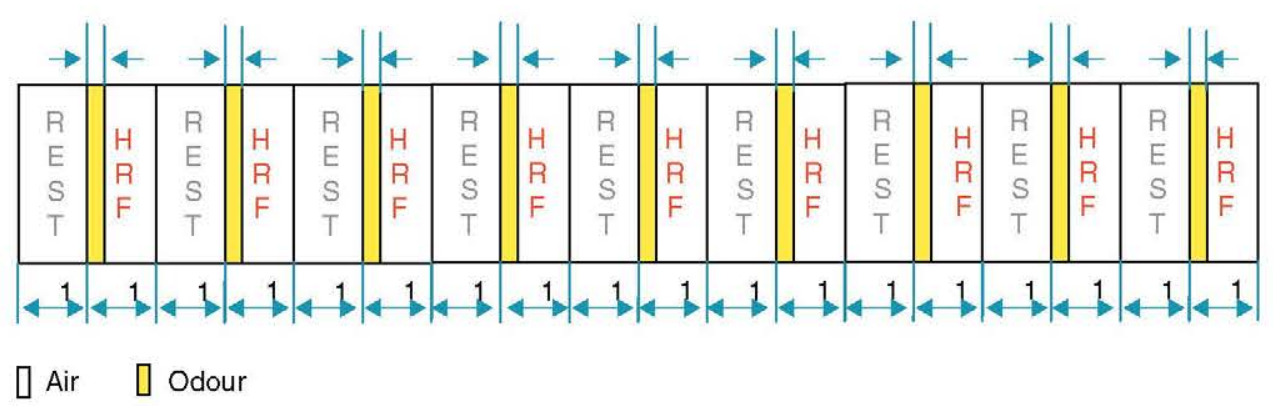

Figure 3 The event-related paradigm used, in which the duration of the activation and resting blocks is $15 \mathrm{~s}$. The duration of the olfactory stimulus (butanol, mint or coffee) is $2 \mathrm{~s}$ for the entire series, consisting of 9 cycles.

\section{Results}

Cortical reactivity was obtained in different brain areas involved in olfactory tasks (Fig. 5). The entorhinal cortex and amygdala, which are related to emotions, showed a higher reactivity than other areas.

With a significance level between $4.5 \%$ and $2 \%$ of BOLD contrast:

1 Entorhinal cortex: $4.5 \%$ BOLD contrast.

2 Amygdala: $3 \%$ BOLD contrast.

3 Insula: $2.5 \%$ BOLD contrast.

4 Putamen: $2.5 \%$ BOLD contrast.

5 Visual cortex: 2\% BOLD contrast.



Figure 4 Haemodynamic response in olfactory functional areas. The image shows how there is an increase in oxygen consumption in the brain area studied when the stimulus is released (green arrow), unlike in the resting phase (red arrow). (For interpretation of the references to colour in this figure legend, the reader is referred to the web version of the article.)

\section{Discussion}

Functional MRI enables us to locate the cortical areas which are activated by different stimuli: visual, ${ }^{12}$ sound ${ }^{13}$ and somatosensory. ${ }^{14}$ In this work we qualitatively and quantitatively demonstrate the activation of different cortical areas in the brains of subjects by normal olfactory stimuli: entorhinal cortex, amygdala, insula, putamen, and visual cortex.

The cortical areas activated are those that have been implicated in the integration of olfactory stimuli, including some regions of the limbic system. The POC area is the most commonly activated: entorhinal cortex and amygdala. We must remember that the POC is not a single area, but rather 5 structurally different regions, located in the ventral and medial surfaces of each brain hemisphere: the anterior olfactory nucleus, amygdala, olfactory tubercle, piriform and periamygdaloid cortex and, finally, the rostral entorhinal cortex. ${ }^{15}$ The amygdala is a heterogeneous structure with numerous nuclei which is located in the anterior temporal lobe. One of these nuclei is the corticomedial nuclear group, which appears to be connected with parts of the hypothalamus involved in regulating food intake, as well as in regulating some reproductive behaviours in animals. ${ }^{15,16}$ Furthermore, the entorhinal cortex is located in the parahippocampal gyrus. It is believed that this area is important in allowing certain scents to evoke past memories. This cortex projects towards the hippocampal formation, which has been found to be essential in converting short-term memories into long-term memories. ${ }^{15,16}$

As for the quantitative study of cortical activation, the results were surprising. If we consider that the gold standard is obtained by measuring the BOLD contrast in motor activation studies (moving a finger or hand and measuring activation of motor cortical areas) with values around $5 \%$, we can conclude that a BOLD contrast of $4.5 \%$ in the entorhinal cortex and $3 \%$ in the amygdala represent considerable activation values for a sensory stimulus. ${ }^{9}$ Therefore, we believe that either the odorous stimulus activates olfactory cortical areas very intensely by itself, or else the stimulation device is so pure and precise that it enables a high-intensity activation image to be collected.One of the main problems in the objective study of smell is the impossibility of controlling some parameters of olfactory stimuli, such as the type of odour, its duration, intensity and frequency. The advantage of the olfactometer is that it enables researchers to vary the stimuli (type of odour, intensity, duration, creating 


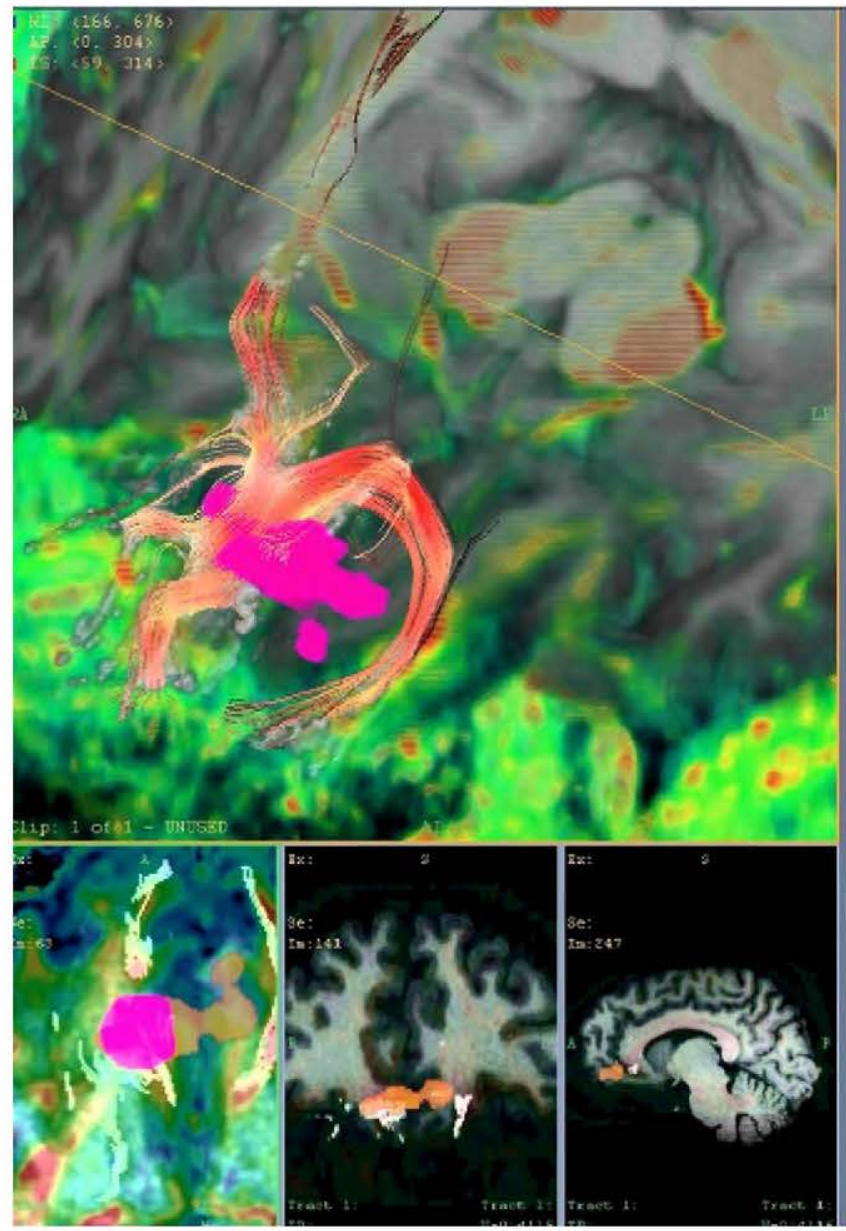

Figure 5 Three-dimensional reconstruction of fibre and cortical activation results in olfactory pathways. The image shows how the olfactory areas of the olfactory bulb, entorhinal cortex, hippocampus and amygdala are activated. In addition, the tractography technique allows us to assess the status of the nerve fibres through which the stimulus travels (yellow arrows). (For interpretation of the references to colour in this figure legend, the reader is referred to the web version of the article.)

predetermined olfactory tasks, etc.) from outside the MRI room without having to distract the patient, and therefore, without creating brain activation distortions or artefacts. In addition, our olfactometer was synchronised with the acquisition of the $f M R I$ device through its trigger signal, thus enabling a perfect synchronisation between stimulus emission and image acquisition. This allowed us to design various olfactory tasks for the study of complex cortical functions: memory, emotions, appetite, sexuality, etc. Devices which stimulate the sense of smell are not new and many are available in the market. ${ }^{17-19}$ The problem is that they are very expensive and difficult to manufacture. At present, we can find some similar devices. ${ }^{10,20-22}$

Olfactometers available in the market have a common design in that they are constructed with metal components, making them bulky and very heavy, thus preventing them from being kept inside the scanner room. This was not a limitation for our olfactometer, since our device is portable and enables the stimuli to be managed from outside the
MRI room. Only the tubes which deploy the stimulus and the mask for the subject need to be kept in the room.

Having an olfactometer available in our consultation will enable us to assess, in an objective manner, the olfactory ability of subjects, either through fMRI or olfactory evoked potentials. It will also allow us to establish correlations between subjective smell tests and objective responses, as well as an objective study of olfactory condition. Murphy et al. ${ }^{23}$ correlated the butanol threshold in the CCCRC olfactory test with evoked potential values obtained using an olfactometer. Lorig et al. ${ }^{24}$ have worked on the correlation between olfactory thresholds in psychophysical tests and their correlation with evoked potentials. Kobal et al. ${ }^{8}$ have used an olfactometer to study anosmic patients through olfactory evoked potentials.

We believe that our olfactometer has room for improvement. The olfactory study lasts no more than $45 \mathrm{~min}$. This time does not differ much from the time it takes to conduct a structural MRI study. However, having patients wear a mask makes them feel more uncomfortable and, possibly, more cramped. On the other hand, the stimulus must travel through a tube into the nose. It is possible that some degradation occurs along the route before the stimulus arrives at the nose. An electronic nose which can measure the exact concentration of the stimulus upon its arrival at both nostrils could be attached to the mask, in order to know the exact concentration which reaches the subject.

Numerous studies still remain to be conducted before normal values for brain activation areas, both quantitative and qualitative, can be established depending on the tasks designed and basic variables such as age and gender. In the future, objective studies of olfaction will open up a very interesting field of study for the early diagnosis of some neuropsychiatric diseases: Parkinson's disease, ${ }^{25,26}$ Alzheimer's disease, ${ }^{27,28}$ eating disorders, sexual disorders, etc.

\section{Financing}

This work was financed by the OLFACTOSENSE Consortium, by the Education Council of the Community of Madrid, the MMA Foundation and the MAPFRE Foundation.

\section{Conflict of Interests}

The authors have no conflicts of interest to declare.

\section{Acknowledgement}

The authors wish to thank Mrs. Eva Alfayate, radiography technician at Fundación Reina Sofía.

Fong K. Olfaction and taste: preface. Otolaryngol Clin North Am. 2004;37:11-2.

Landis BN, Konnerth CG, Hummel T. A study on the frequency of olfactoy dysfunction. Laryngoscope. 2004;114:1764-9.

Toledano A, González E, Herráiz C. Alteraciones del olfato en la consulta generald e Otorrinolaringología. Acta Otorrinolaringol Esp. 2002;53:653-7. 
Hadley K, Orlandi RR, Fong KJ. Basic anatomy and physiology of olfaction and taste. Otolaryngol Clin North Am. 2004;37:1115-26.

Mata J, Jiménez J, Postigo A. Potenciales evocados corticales olfatorios. Acta Otorrinolaringol Esp. 1998;49:385-7.

Allison T, Goff WR. Human cerebral evoked responses to odorous stimuli. Electroencephalogr Clin Neurophysiol. 1967;23:78.

Hummel T, Knecht M, Kobal G. Peripherally obtained electrophysiological responses to olfactory stimulation in man: electro-olfactograms exhibit a smaller degree of desensitization compared with subjective intensity estimates. Brain Res. 1996;717:160-4.

Kobal G, Hummel T. Olfactory and intranasal trigeminal event-related potencials in anosmic patients. Laryngoscope. 1998;108:1033-5.

Tabert MH, Steffener J, Albers MW, Kern DW, Michael $M$, Tang $H$, et al. Validation and optimization of statistical approaches for modelling odorant-induced fMRI signal changes in olfactory-related brain areas. Neuroimage. 2007;34: 1375-90.

Vigouroux M, Bertrand B, Farget V, Plailly J, Royet JP. A stimulation method using odors suitable for PET and fMRI studies with recording of physiological and behavioral signals. J Neurosci Methods. 2005;142:35-44.

Página web del University College of London, Statistical Parametric Mapping; 2011. Available from: http://www.fil.ion.ucl.ac.uk/spm/

Zeki S, Watson JDG, Lueck EJ, Friston KJ, Kennard C, Frackowiack RSJ. A direct demonstration of functional specialization in human visual cortex. J Neurosci. 1991;11: 641-9.

Berry I, Démonet JF, Warach S, Viallard G, Boulanouar K, Franconi $\mathrm{JM}$, et al. Activation of association auditory cortex demonstrated with functional MRI. Neuroimage. 1995;2: 215-9.

Ogawa S, Tank DW, Menon R, Ellermann JM, Kim SG, Merkle $\mathrm{H}$, et al. Intrinsic signal changes accompanying sensory stimulation: functional brain mapping with magnetic resonance imaging. Proc Natl Acad Sci USA. 1992;89:5951-5.

Carpenter MB. Fundamentos de Neuroanatomía. Segunda edición, capítulo 12: vías olfatorias, formación del hipocampo y amígdala. Buenos Aires: El Ateneo; 1985. p. 272-4.
Hadley K, Orlandi RR, Fong KJ. Basic anatomy and physiology of olfaction and taste. Otolaryngol Clin North Am. 2004;37:1115-26.

López-Ávila A, Rincón F. Diseño de un olfatómetro de flujo de aire para medir respuestas olfativas de insectos de tamaño mediano y pequeño. Revista Corpoica Ciencia y Tecnología Agropecuaria. 2006;1:61-5.

Turlings T, Davison A, Tamó C. A sixarm olfactometer permitting simultaneous observation of insect attraction and odour trapping. Physiol Entomol. 2004;29:45-55.

Vet LEM, Lenteren Van JC, Heymans M, Meelis E. An airflow olfactometer for measuring olfactory responses of hymenopterous parasitoids and other small insects. Physiol Entomol. 1983;8:97-106.

Doarn CR, Adilova F, Lam D. A review of telemedicine in Uzbekistan. J Telemed Telecare. 2005;11:135-9.

Popp R, Sommer M, Müller J, Hajak G. Olfactometry in fMRI studies: odor presentation using nasal continuous positive airway pressure. Acta Neurobiol Exp (Wars). 2004;64:171-6.

Lowen SB, Lukas SE. A low-cost: MR-compatible olfactometer. Behav Res Methods. 2006;38:307-13.

Murphy C, Nordin S, de Wijk RA, Cain WS, Polich J. Olfactory-evoked potentials: assessment of young and elderly and comparison to psychophysical threshold. Chem Senses. 1994:19:47-56.

Lorig TS, Matia DC, Peszka J, Bryant DN. The effects of active and passive stimulation on chemosensory event-related potentials. Int J Psychophysiol. 1996;23:199-205.

Ponsen MM, Stoffers D, Booij J, Van Eck-Smith BL, Wolters EC, Berendse HW. Idiopathic hyposmia as a preclinicalsign of Parkinson's disease. Ann Neurol. 2004;56:173-81.

Barz S, Hummel T, Pauli E, Majer M, Lang CJ, Kobal G. Chemosensory event-related potentials in response to trigeminal and olfactory stimulation in idiopathic Parkinson's disease. Neurology. 1997;49:1424-31.

Sakuma K, Nakashima K, Takahashi K. Olfactory evoked potentials in Parkinson's disease, Alzheimer's disease and anosmic patients. Psychiatry Clin Neurosci. 1996;50:35-40.

Royall DR, Chiodo LK, Polk MS, Jaramillo CJ. Severe dysosmia is specifically associated with Alzheimer-like memory deficits in nondemented elderly retirees. Neuroepidemiology. 2002;21:68-73. 